\title{
Nitrogen Fixation in the Eastern Tropical South Pacific
}

\section{Datasets:}

- $\quad 15 N 2$ incubation-based N2 fixation rates in the Eastern Tropical South Pacific

- $\quad$ Nitrate plus nitrite concentration and d15N in the Eastern Tropical South Pacific

- Sediment trap PN mass flux and isotopic composition in the Eastern Tropical South Pacific

\section{Dataset: nitrate plus nitrite}

Projects:

Expression of Microbial Nitrification in the Stable Isotopic Systematics of Oceanic Nitrite and Nitrate (Microbial Nitrification)

Documenting N2 fixation in N deficient waters of the Eastern Tropical South Pacific (N2 fixation ETSP)

Lead Principal Investigator:

Dr Douglas Capone (University of Southern California, USC-WIES)

Principal Investigator:

Dr William M. Berelson (University of Southern California, USC-WIES)

Dr Karen L. Casciotti (Woods Hole Oceanographic Institution, WHOI)

Dr Dennis Hansell (University of Miami Rosenstiel School of Marine and Atmospheric Science, UM-RSMAS)

Co-Principal Investigator:

Dr Angela Knapp (University of Miami Rosenstiel School of Marine and Atmospheric Science, UM-RSMAS)

Contact:

Dr Angela Knapp (Florida State University, FSU - Oce)

Validated: No

Data version: 2015-04-09

Version Date: 04/09/2015

Current State: Restricted

\section{Description}

Brief Description: Nitrate + nitrite concentration and d15N from the Eastern Tropical South Pacific, 2010-2011

These data are restricted until manuscript is accepted for publication. Please contact PI for further information.

\section{Acquisition Description}

Water column sample collection: Samples were collected on the R/V Atlantis in January through February 2010, and the R/V Melville in March through April 2011 on a zonal transect along 20 S between 80 W and 100 W, with exact station locations and sample depths, nutrient concentrations and isotopic compositions reported below. Water column samples were collected by Niskin bottles deployed on a rosette equipped with conductivity-temperature-depth (CTD) sensors. All samples were collected into acid-washed, sample-rinsed HDPE bottles, and samples from the upper $400 \mathrm{~m}$ passed a 0.2 $\mu \mathrm{m}$ filter before collection. All samples were stored at -20 O C until analysis on land.

Nitrate plus nitrite (NO3-+NO2-) concentration: The concentration of NO3-+NO2- ([NO3-+NO2-]) was determined using chemiluminescent analysis (in a configuration with a detection limit of $0.05 \mu \mathrm{M},+0.1 \mu \mathrm{M} 1$ S.D.).

Reference: Braman, R. S. \& Hendrix, S. A. Nanogram Nitrite and Nitrate Determination in Environmental and BiologicalMaterials by Vanadium(lii) Reduction with Chemi-Luminescence Detection. Analytical Chemistry 61, 2715-2718 (1989). 
NO3+NO2 d15N: The d15N of NO3+NO2 was determined using the denitrified method on samples with $>0.3 \mu \mathrm{M}$ $\mathrm{NO} 3+\mathrm{NO} 2$ with a standard deviation $<0.2$ per mil.

\section{References:}

Sigman, D. M. et al. A bacterial method for the nitrogen isotopic analysis of nitrate in seawater and freshwater. Analytical Chemistry 73, 4145-4153 (2001).

Casciotti, K. L., Sigman, D. M., Hastings, M. G., Bohlke, J. K. \& Hilkert, A. Measurement of the oxygen isotopic composition of nitrate in seawater and freshwater using the denitrifier method. Analytical Chemistry 74, 4905-4912 (2002).

Mcllvin, M. R. \& Casciotti, K. L. Technical Updates to the Bacterial Method for Nitrate Isotopic Analyses. Analytical Chemistry 83, 1850-1856 (2011).

\section{Processing Description}

\section{BCO-DMO Processing:}

- added conventional header with dataset name, PI name, version date

- renamed parameters to BCO-DMO standard

- added cruise id column

- replaced blank cells with nd

\section{Funding Sources}

\section{Funding Source Award Number}

NSF Ocean Sciences OCE-0850801

NSF Ocean Sciences OCE-0961098

$\underline{\text { NSF Ocean Sciences OCE-0850905 }}$

\section{Deployments}

Deployment

$\underline{\text { AT15-61 }}$

Synonyms

- ETSP2010

$\underline{\mathrm{MV} 1104}$

\section{Start Date Platform}

29 Jan 2010 R/V Atlantis Dr Douglas Capone (Chief Scientist)

Dr William M. Berelson (Co-Chief Scientist) 23 Mar $2011 \underline{\text { R/V Melville }} \underline{\text { Dr William M. Berelson (Chief Scientist) }}$ data info

$\underline{\text { data info }}$

Instruments

CTD profiler

Short Name: CTD

Community Standard Description

\section{Generic Description}

The Conductivity, Temperature, Depth (CTD) unit is an integrated instrument package designed to measure the conductivity, temperature, and pressure (depth) of the water column. The instrument is lowered via cable through the water column and permits scientists observe the physical properties in real time via a conducting cable connecting the CTD to a deck unit and computer on the ship. The CTD is often configured with additional optional sensors including fluorometers, transmissometers and/or radiometers. It is often combined with a Rosette of water sampling bottles (e.g. Niskin, GO-FLO) for collecting discrete water samples during the cast. This instrument designation is used when specific make and model are not known.

PI supplied instrument name: CTD

Dataset-specific description 


\section{Supplied Name}

date

station

lat

lon

depth

sigma theta

$\mathrm{NO} 3 \mathrm{NO} 2$

$\mathrm{NO} 3 \mathrm{NO} 2 \mathrm{sd}$

del15N NO3NO2

del15N NO3NO2 sd

\section{Supplied description}

sample collection date (local)

station

latitude; north is positive

longitude; east is positive

sample depth

seawater density

nitrate + nitrite concentration

nitrate + nitrite concentration standard deviation

delta $15 \mathrm{~N}$ of nitrate + nitrite, reported in units of permil vs. atmospheric N2

delta $15 \mathrm{~N}$ of nitrate + nitrite; 1 standard deviation, reported in units of permil vs. atmospheric N2

\section{Supplied Units Standard Name}

yyyy-mm-dd date_local

unitless sta

decimal degrees lat

decimal degrees lon

meters depth

unitless sigma_theta

micro mols N NO3_NO2

micro mols $\mathrm{N}$

per liter

std_dev

per mil versus

air

del15N_NO3NO2

per mil versus

air std_dev 


\section{Dataset: nitrogen fixation rates}

Project:

Documenting N2 fixation in N deficient waters of the Eastern Tropical South Pacific (N2 fixation ETSP)

Lead Principal Investigator:

Dr Douglas Capone (University of Southern California, USC-WIES)

Principal Investigator:

Dr William M. Berelson (University of Southern California, USC-WIES)

Dr Dennis Hansell (University of Miami Rosenstiel School of Marine and Atmospheric Science, UM-RSMAS)

Co-Principal Investigator:

Dr Angela Knapp (University of Miami Rosenstiel School of Marine and Atmospheric Science, UM-RSMAS)

Contact:

Dr Angela Knapp (Florida State University, FSU - Oce)

Validated: No

Data version: 2015-04-09

Version Date: 04/09/2015

Current State: Restricted

\section{Description}

Brief Description: 15N2-based N2 fixation rates from the Eastern Tropical South Pacific, 2010-2011

These data are restricted until manuscript is accepted for publication. Please contact PI for further information.

\section{Acquisition Description}

Water column sample collection: Samples were collected on the R/V Atlantis in January through February 2010, and the R/V Melville in March through April 2011 on a zonal transect along 20 S between $80 \circ \mathrm{W}$ and $100 \circ \mathrm{W}$, with exact station locations and sample depths, nutrient concentrations and isotopic compositions reported below. Water column samples were collected by Niskin bottles deployed on a rosette equipped with conductivity-temperature-depth (CTD) sensors. All samples were collected into acid-washed, sample-rinsed HDPE bottles, and samples from the upper $400 \mathrm{~m}$ passed a 0.2 $\mu \mathrm{m}$ filter before collection. All samples were stored at $-200 \mathrm{C}$ until analysis on land.

15N2 fixation rate measurements: Short-term N2 fixation rate measurements incubated with 15N2 gas from Sigma Aldrich (lot \#s SZ1670V and MBBB0968V) were carried out in acid-washed, sample-rinsed light transparent $4 \mathrm{~L}$ polycarbonate bottles amended with $1.5 \mathrm{~mL}$ of $99 \% 15 \mathrm{~N} 2$ and $1.5 \mathrm{~mL}$ of $0.5 \mathrm{M} \mathrm{NaH} 13 \mathrm{CO}$. Incubations were performed under simulated in situ conditions of temperature and light and run for staggered periods (e.g. 0, 12, 24 and $48 \mathrm{hrs}$ ). Incubations were terminated by filtration of the $4 \mathrm{~L}$ sample onto a precombusted $25 \mathrm{~mm}$ Whatman GF/F, which was then analyzed by mass spectrometry at the University of Southern California for d15N and d13C. During ESTP 1, periodic time zero incubations were measured, with samples filtered within 5 to 10 minutes of injection of $15 \mathrm{~N} 2$. Zero time enrichments were typically near natural abundance levels with the greatest observed enrichment in 8 experiments at $23 \%$, essentially at natural abundance level for our tracer experiments. We assumed natural abundance $(0.3663$ atom $\%)$ for calculations. Limits of detection are about 10-14 $\mu \mathrm{g}$ for $\mathrm{N}$ and 6-10 $\mu \mathrm{g}$ for $\mathrm{C}$. Reproducibility as the standard deviation for isotopic analysis is about $\pm 0.3 \%$ for $\mathrm{d} 15 \mathrm{~N}$ and $\pm 0.2 \%$ for $\mathrm{d} 13 \mathrm{C}$, and about $\pm 0.1-0.2 \mu \mathrm{g}$ for mass determinations.

Reference: Montoya, J. P., Voss, M., Kahler, P. \& Capone, D. G. A simple, high-precision, high-sensitivity tracer assay for N-2 fixation. Applied and Environmental Microbiology 62, 986-993 (1996).

\section{Processing Description}

\section{BCO-DMO Processing:}


- added conventional header with dataset name, PI name, version date

- renamed parameters to BCO-DMO standard

- added cruise id column

\section{Funding Sources}

\section{Funding Source Award Number}

NSF Ocean Sciences OCE-0850801

NSF Ocean Sciences

\section{Deployments}

Deployment

$\underline{\text { AT15-61 }}$

$\underline{M V 1104}$

Synonyms

- ETSP2010

- $\quad$ ETSP2011

\section{Start Date Platform Investigator}

29 Jan 2010 R/V Atlantis Dr Douglas Capone (Chief Scientist)

Dr William M. Berelson (Co-Chief Scientist) data info

23 Mar $2011 \underline{\text { R/V Melville }} \frac{\text { Dr William M. Berelson (Chief Scientist) }}{\text { Dr Angela Knapp (Co-Chief Scientist) }}$

$\underline{\text { Instruments }}$

CTD profiler

Short Name: CTD

Community Standard Description

Generic Description

The Conductivity, Temperature, Depth (CTD) unit is an integrated instrument package designed to measure the conductivity, temperature, and pressure (depth) of the water column. The instrument is lowered via cable through the water column and permits scientists observe the physical properties in real time via a conducting cable connecting the CTD to a deck unit and computer on the ship. The CTD is often configured with additional optional sensors including fluorometers, transmissometers and/or radiometers. It is often combined with a Rosette of water sampling bottles (e.g. Niskin, GO-FLO) for collecting discrete water samples during the cast. This instrument designation is used when specific make and model are not known.

PI supplied instrument name: CTD

Dataset-specific description

\section{Gas Chromatograph}

Short Name: Gas Chromatograph

Community Standard Description

\section{Generic Description}

Instrument separating gases, volatile substances, or substances dissolved in a volatile solvent by transporting an inert gas through a column packed with a sorbent to a detector for assay. (from SeaDataNet, BODC)

PI supplied instrument name: Gas Chromatograph

Dataset-specific description

\section{Parameters}

\section{Supplied Name}

date

station

$\underline{\text { lat }}$

lon

depth
Supplied description

sample collection date (local)

station

latitude; north is positive

longitude; east is positive

sample depth

Nfix umol N m2 d $24 \mathrm{hr} 15 \mathrm{~N} 2$ fixation rate

\section{Supplied Units Standard Name}

yyyy-mm-dd date_local

unitless sta

decimal degrees lat

decimal degrees lon

meters depth

umol N m-2 d-1 N2_fix

Nfix stdev

$24 \mathrm{hr} 15 \mathrm{~N} 2$ fixation rate standard deviation umol N m-2 d-1 std_dev 


\section{Dataset: sediment trap PN flux}

Project:

Documenting N2 fixation in N deficient waters of the Eastern Tropical South Pacific (N2 fixation ETSP)

Lead Principal Investigator:

Dr Douglas Capone (University of Southern California, USC-WIES)

Principal Investigator:

Dr William M. Berelson (University of Southern California, USC-WIES)

Dr Dennis Hansell (University of Miami Rosenstiel School of Marine and Atmospheric Science, UM-RSMAS)

Co-Principal Investigator:

Dr Douglas Hammond (University of Southern California, USC)

Dr Angela Knapp (University of Miami Rosenstiel School of Marine and Atmospheric Science, UM-RSMAS)

Scientist:

Dr Masha Prokopenko (University of Southern California, USC-WIES)

Contact:

Dr Angela Knapp (Florida State University, FSU - Oce)

Validated: No

Data version: 2015-04-09

Version Date: 04/09/2015

Current State: Restricted

Description

Brief Description: PNsink mass flux and d15N from floating sediment trap deployments

These data are restricted until manuscript is accepted for publication. Please contact PI for further information.

\section{Acquisition Description}

Sinking particulate nitrogen (PNsink) mass and d15N analysis: Sinking particulate material was collected using surfacetethered floating particle-interceptor traps (PIT) equipped with 12 polycarbonate cylinders, deployed for up to 70 hours. Floating sediment traps were deployed at $200 \mathrm{~m}$ at Stations 3 and 5 on the 2010 cruise; for all other stations, traps were deployed at $100 \mathrm{~m}$. Sediment trap samples were collected into a brine solution and then filtered and split into replicate samples. In most cases, two splits were collected from each sediment trap, one of which was acidified to remove inorganic carbon. In 2010 filtration removed the contribution of "swimmers" from sediment trap material. On the 2011 cruise, "swimmers" were identified by dissecting microscopy and hand-picked from sediment trap samples using sterilized micropipettors and forceps to remove their isotopic contribution to the sinking flux. Mass and isotopic fluxes were determined by dividing the mass of sinking particulate material captured in each trap by the trap surface area and by the duration (hrs) of trap deployment. Subsequently, the total mass flux was multiplied by the \%N determined by combustion analysis of trap samples at the UC Davis Stable Isotope Facility to calculate PNsink mass fluxes; the d15N of trap samples was determined at the same time. The limit of detection for combustion analysis is $1.5 \mu$ mols $\mathrm{N}$ and the precision of the $\mathrm{d} 15 \mathrm{~N}$ measurement is $+0.3 \%$. No systematic difference was observed in the $\mathrm{d} 15 \mathrm{~N}$ of acidified vs. nonacidified trap samples.

\section{References:}

Soutar, A., Kling, S. A., Crill, P. A. \& Duffrin, E. MONITORING MARINE-ENVIRONMENT THROUGH SEDIMENTATION. Nature 266, 136-139, doi:10.1038/266136a0 (1977).

Knauer, G. A., Martin, J. H. \& Bruland, K. W. Fluxes of particulate carbon, nitrogen, and phosphorus in the upper water column of the northeast Pacific. Deep-Sea Research 26, 97-108, doi:10.1016/0198-0149(79)90089-X (1979). 


\section{BCO-DMO Processing:}

- added conventional header with dataset name, PI name, version date

- renamed parameters to BCO-DMO standard

- added cruise id column

- replaced blank cells with nd

Funding Sources

Funding Source Award Number

NSF Ocean Sciences OCE-0850801

NSF Ocean Sciences $\underline{\text { OCE-0850905 }}$

\section{Deployments}

Deployment

Synonyms

Start Date Platform

Investigator

$\underline{\text { AT15-61 }}$

- $\quad$ ETSP2010

$\underline{\text { MV1104 }}$

- ETSP2011

29 Jan 2010 R/V Atlantis Dr Douglas Capone (Chief Scientist)

Dr William M. Berelson (Co-Chief Scientist) data info

23 Mar $2011 \underline{\text { R/V Melville }} \underline{\text { Dr William M. Berelson (Chief Scientist) }} \underline{\text { data info }}$

Instruments

Microscope-Optical

Short Name:

Community Standard Description

\section{Generic Description}

Instruments that generate enlarged images of samples using the phenomena of reflection and absorption of visible light. Includes conventional and inverted instruments. Also called a "light microscope".

PI supplied instrument name: dissecting microscope

Dataset-specific description

Sediment Trap - Floating

Short Name: Sed Trap - Float

Community Standard Description

\section{Generic Description}

Floating sediment traps are specially designed sampling devices deployed to float in the water column (as opposed to being secured to a mooring at a fixed depth) for periods of time to collect particles from the water column that are falling toward the sea floor. In general a sediment trap has a container at the bottom to collect the sample and a broad funnel-shaped opening at the top with baffles to keep out very large objects and help prevent the funnel from clogging. The 'Sediment Trap -Floating' designation is used for a floating type of sediment trap about which no other design details are known.

PI supplied instrument name: Sed Trap - Float

Dataset-specific description

\section{Parameters}

\begin{tabular}{ll}
\multicolumn{1}{c}{ Supplied Name } & \multicolumn{1}{c}{ Supplied description } \\
$\frac{\text { date }}{\underline{\text { station }}}$ & sample collection date (local) \\
$\underline{\text { lat }}$ & station \\
$\underline{\text { lon }}$ & latitude; north is positive \\
$\underline{\text { depth }}$ & longitude; east is positive \\
traps per depth & Depth trap was deployed \\
\cline { 2 - 3 } & Number of traps deployed per depth (Total \# sample splits)
\end{tabular}

\begin{tabular}{|c|c|}
\hline Supplied Units & $\frac{\text { Standard }}{\text { Name }}$ \\
\hline $\begin{array}{l}\text { yyyy-mm-dd } \\
\text { unitless }\end{array}$ & $\begin{array}{l}\text { date_local } \\
\text { sta }\end{array}$ \\
\hline $\begin{array}{l}\text { decimal degrees } \\
\text { decimal degrees }\end{array}$ & \\
\hline $\begin{array}{l}\text { meters } \\
\text { unit }\end{array}$ & $\begin{array}{l}\text { depth } \\
\text { num_reps }\end{array}$ \\
\hline
\end{tabular}


Supplied Name

duration Length of trap deployment

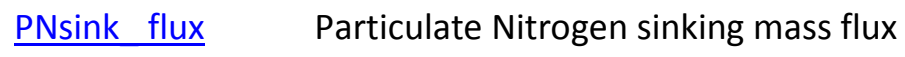

PNsink flux sd Particulate Nitrogen sinking mass flux; 1 standard deviation

del15N PNsink Particulate Nitrogen sinking flux d15N (per mil relative to N2 in air)

del15N PNsink sd Particulate Nitrogen sinking flux d15N (per mil relative to $\mathrm{N} 2$ in air);

1 standard deviation

\section{Supplied Units $\quad \underline{\text { Standard }}$}

hours duration

milli mol N m-2 PNsink

d-1

milli mol N m-2

d-1

std_dev

per mil

del15N_PNsink

per mil

std_dev 